\title{
Use Of Quantitative Modelling To Elucidate The Roles Of The Liver, Gut, Kidney, And Muscle In Ammonia Homeostasis And How Lactulose And Rifaximin Alter This Homeostasis
}

This article was published in the following Dove Press journal:

International Journal of General Medicine

\section{Michael D Levitt' \\ David G Levitt ${ }^{2}$}

'Research Service, Veterans Affairs Medical Center, Minneapolis, MN 554I7, USA; ${ }^{2}$ Department of Integrative Biology and Physiology, University of Minnesota, Minneapolis, MN 55455, USA
Correspondence: David G Levitt Department of Integrative Biology and Physiology, University of Minnesota, 6-125 Jackson Hall, 32I Church St. S. E.,

Minneapolis, MN 55455, USA

Tel + | 6125940272

Fax +1612301 1543

Email levit00I@umn.edu

\begin{abstract}
Humans must eliminate approximately $1 \mathrm{M}$ of ammonia per day while maintaining the blood concentration of this potent neurotoxin at a concentration of only about $30 \mu \mathrm{M}$. The mechanisms producing such effective ammonia homeostasis are poorly understood by clinicians due to the multiple organs (liver, gut, kidney and muscle) involved in ammonia homeostasis. Based on literature values we present a novel, simplified description of normal and disordered ammonia and the potential mechanisms whereby the drugs used to treat hepatic encephalopathy, lactulose and rifaximin, lower the blood ammonia concentration. Concepts discussed include the following: 1$)$ only about $44 \mathrm{mmol}$ of ammonia/day (4.4\% of total production) reaches the peripheral circulation due to the efficient linkage of amino deamination and the urea cycle in hepatic mitochondria; 2) the gut and kidney contribute roughly equally to delivery of this $44 \mathrm{mmol} /$ day to systemic blood; 3) the bulk of gut ammonia production seemingly originates in the small bowel from bacterial deamination of urea by bacteria and mucosal deamination of circulating and ingested glutamine; 4) the apparent production of ammonia in the small bowel markedly exceeds that quantity that enters the portal blood, indicating that ammonia disposal mechanisms in the small bowel play a major role in ammonia homeostasis. With regard to the hyperammonemia of chronic liver disease: 1) shunting of portal blood around the liver, by itself, can account for commonly observed ammonia elevations; 2) severe portal hypertension causes an increased release of ammonia by the kidney; 3) high blood ammonia is associated with an unexplained massive increase in the muscle uptake of ammonia that could play an important role in limiting hyperammonemia; and 4) a major action of lactulose administration may be the enhancement of ammonia uptake by small bowel bacteria, while the mechanism of action of rifaximin is unclear.
\end{abstract}

Keywords: encephalopathy, urease, glutamine, deamination, urea

\section{Introduction}

Confronted with a cirrhotic patient with overt or suspected hepatic encephalopathy, the clinician routinely prescribes lactulose and/or rifaximin in the belief that these drugs will reduce the serum ammonia concentration and improve the encephalopathy. Each of these suppositions is correct - controlled trials in chronic liver disease (CLD) have shown that these drugs reduce hyperammonemia by $20-50 \%$ and improve the encephalopathy. ${ }^{1-5}$ Fortunately, prescribing lactulose and rifaximin 
does not require a precise understanding of how these drugs alter ammonia physiology since most clinicians have only a rudimentary understanding of the complexities of ammonia homeostasis. Adding to this problem is the controversy in the literature concerning how these drugs reduce the serum ammonia concentration and the importance of ammonia to the pathogenesis of the encephalopathy of CLD.

Recently, drugs such as the ammonia-scavenging compounds benzoate, phenylacetate and phenylbutyrate have been used for treating cirrhotic encephalopathy (HE). ${ }^{6}$ For example, in a randomized study, phenylbutyrate showed significant benefits in patients not being treated with rifaximin but no benefit to patients on rifaximin. ${ }^{7}$ However, because these drugs are much more rarely used and have a completely different mechanism of action, this review will focus on lactulose and rifaximin.

Ammonia homeostasis is complicated because it is a central element in organ nitrogen fluxes. We recently reviewed the world's literature on the physiology of ammonia, providing a complete quantitative accounting of the individual organ ammonia, urea, glutamine and alanine net flux, in an attempt to quantitatively model ammonia homeostasis. ${ }^{8}$ (Studies using tracer 13N-labeled $\mathrm{NH}_{3}$ are not useful because the $\mathrm{N}$ of $\mathrm{NH}_{3}$ exchanges rapidly (seconds) with many amino acids. ${ }^{9,10}$ ) This effort suggested that describing ammonia production and elimination in quantitative terms simplifies understanding of ammonia physiology. The goals of this paper are to: first, provide what we believe to be a novel, quantitative approach to explaining ammonia homeostasis that (we hope) will be intelligible to the clinician; second, based on this information, attempt to identify the mechanism(s) by which lactulose and rifaximin reduce the serum ammonia concentration; and, lastly, conclude with a very brief discussion of the role of ammonia in the encephalopathy of CLD.

\section{Basics Of Ammonia Production And Elimination}

The quantity of ammonia that must be produced each day by human subjects can be calculated from the dietary intake of protein, which for Americans averages about $85 \mathrm{~g} /$ day. (For simplification, throughout this paper we utilize selected literature values rather than ranges for various parameters of ammonia physiology, hence the discussion should be considered to be illustrative rather a precisely accurate representation of ammonia homeostasis). Since protein is about $16 \%$ nitrogen, in the steady state subjects ingest and then must excrete about $13.6 \mathrm{~g}$ or 1.0 mole of nitrogen per day. The vast majority of nitrogen excretion requires deamination of amino acids with the daily release of about 1 mole of ammonia, yet the systemic blood concentration of this potent neurotoxin normally is maintained at the remarkably low concentration of about $30 \mu \mathrm{M}$. For comparison, the normal bilirubin production of only $0.5 \mathrm{mmol} / \mathrm{day}(1 /$ 2000 of that of ammonia) is associated with a serum bilirubin concentration of about $20 \mu \mathrm{M}$ (similar to that of ammonia). Assuming that all ammonia destined to be excreted entered the peripheral circulation, the clearance of ammonia - calculated from the elimination rate $(1 \mathrm{M} /$ day)/systemic blood concentration $(30 \mu \mathrm{M})$ - yields the impossibly high value of $20 \mathrm{~L} /$ minute or 4 times the cardiac output (the maximal possible clearance rate). Thus, it is apparent that most of the excreted ammonia never reaches the peripheral blood in the form of free ammonia.

The rate that ammonia is delivered to the systemic circulation can be calculated from its elimination rate since, in the steady-state, delivery and elimination rates must be equal. The vast majority of ammonia extraction from blood occurs in the liver. The efficiency of this extraction is on the order of $70 \%,{ }^{11}$ ie, $70 \%$ of the ammonia delivered to the liver is removed and $30 \%$ passes out in the hepatic vein. Since total liver blood flow is about $1.5 \mathrm{~L} / \mathrm{min},{ }^{12}$ the ammonia clearance of peripheral blood is calculated from: $00.70 \times$ $1.50 \mathrm{~L} / \mathrm{min}$ or about $1 \mathrm{~L} / \mathrm{min}$, which extrapolates to 1440 liters per day, ie, 1440 liters of blood is completely "cleared" of ammonia each day. It follows that the rate that ammonia normally is removed from the peripheral blood (ammonia concentration of $30 \mu \mathrm{M}$ ) equals $30 \mu \mathrm{mol} / \mathrm{L} \times 1440 \mathrm{~L} /$ day or $43 \mathrm{mmol} /$ day. To understand ammonia homeostasis, it is important to appreciate that of the $1000 \mathrm{mmol}$ of ammonia that must be eliminated from the body each day, normally only about $43 \mathrm{mmol} /$ day or $4.3 \%$ ever reaches the peripheral circulation as ammonia.

\section{How Does The Body Limit Access Of Ammonia To The Systemic Circulation?}

Even if all ammonia production occurred in the GI tract (which is not the case) and were delivered via portal blood flow to the liver, the $30 \%$ of the ammonia not removed in the initial pass would produce a steady-state ammonia concentration of $208 \mu$ moles/L in peripheral blood, an 
encephalopathic concentration. It follows that the vast majority of ammonia released from amino acids must occur in a "compartment" in which metabolism to a excretable compound occurs without the ammonia ever reaching the blood. This "compartment" is the hepatic mitochondria wherein the deamination of amino acids is so closely linked to the initial reactions of the urea cycle enzyme system that virtually no ammonia escapes into hepatic venous blood flow. Evidence for this tight linkage is provided by measurements made during massive intravenous infusion of amino acids into healthy subjects: serum ammonia did not increase whereas the serum urea concentration and the urinary excretion of urea quadrupled. ${ }^{13}$ Thus, as long as the urea cycle is functioning normally, blood ammonia concentration is minimally influenced by the rate of deamination of amino acids in the liver but rather is a function of the small fraction of the ammonia released in extra-hepatic sites. The importance of this concept is illustrated by a theoretical patient with a urinary infection with urease producing organisms (a very rare cause of hyperammonemia). If such an infection released $100 \mathrm{mmol}$ of ammonia per day, one might postulate (incorrectly) that this amount of ammonia would only increase the total daily ammonia load of 1 mole by $10 \%$, and hence produce a negligible $10 \%$ increase in serum ammonia. In fact, this $100 \mathrm{mmol}$ of ammonia, released directly into the systemic circulation, more than triples the $43 \mathrm{mmol} /$ day of ammonia normally reaching peripheral blood and hence could roughly triple the blood ammonia concentration.

\section{Extrahepatic Sites Of Ammonia Production And Uptake}

The major extrahepatic sites of ammonia release are the gut and the kidney. The ammonia concentration of portal blood is about three times greater than that of systemic blood, ie, the blood concentration of ammonia rises by $60 \mu \mathrm{m} / \mathrm{L}$ as it traverses the gut. ${ }^{14}$ Given the portal vein flow of $1 \mathrm{~L} / \mathrm{min}$, the gut delivers about $60 \mu \mathrm{m}$ of ammonia per minute, or $85 \mathrm{mmol} /$ day to the circulation. Normally, $30 \%$ of this ammonia escapes first-pass clearance in the liver, with the delivery of about $26 \mathrm{mmol} /$ day to the peripheral circulation. Given that the total amount of ammonia normally reaching the peripheral circulation previously was calculated to be about $43 \mathrm{mmol} / \mathrm{day}$, gut ammonia is a major, but not the sole, source of systemic ammonia. The kidney appears to deliver about 22 moles/day of ammonia to the blood ${ }^{15}$ while muscle normally removes a small quantity. ${ }^{8}$ Ammonia from the kidney is released directly into the peripheral circulation, which roughly triples its contribution to the peripheral blood concentration relative to the $86 \mathrm{mmol} /$ day production entering the blood from the gut, of which only $30 \%$ escapes first pass metabolism in the liver. Thus, the ammonia contributions of the kidney ( $22 \mathrm{mmol} /$ day) and gut ( $26 \mathrm{mmol} /$ day) to peripheral blood are roughly equal in healthy subjects. As will be discussed, shunting of blood around the liver in chronic liver disease reduces the first-pass clearance of gutderived ammonia, and the intestine becomes an increasingly important source of systemic ammonia.

\section{Production Of Ammonia In The Gut}

Nitrogen-containing compounds that potentially could serve as substrates for gut ammonia production include urea, circulating glutamine, and luminal protein/amino acids.

\section{Urea Catabolism}

The major route of elimination of ammonia is via the urinary excretion of urea. Studies with isotopically labelled urea have shown that about $20 \%$ of the urea production is catabolized prior to excretion in the urine. ${ }^{16-18}$ This catabolism requires the action of urease, an enzyme not produced by mammalian tissue. Thus, bacterial urease seemingly must be responsible for urea catabolism, an assumption supported by the absence of urea catabolism in germ free animals. ${ }^{19}$ The gut seemingly is the only organ with sufficient bacterial contamination to account for urea catabolism.

Since urea passively diffuses into the gut, it might be expected that the rate of urea catabolism would be proportional to the blood urea concentration. Surprisingly, this is not the case, at least at normal to high concentrations of blood urea. The percentage of the urea catabolized falls in proportion to increasing blood urea concentration such that the absolute quantity of urea catabolized remains normal. If this were not the case, patients with renal failure and markedly elevated blood urea concentrations routinely would be hyperammonemic (which they are $\operatorname{not}^{20}$ ). A variety of studies $^{8}$ have suggested that the colon is very impermeable to urea relative to the small bowel, which has urea concentrations roughly equal to that of blood. ${ }^{21}$ Thus, urea catabolism appears to take place primarily in the upper gut. The simplest explanation for the failure of urea catabolism to rise with increasing blood urea concentrations is that the rate of diffusion of urea from the blood to gut at normal 
blood urea concentration is sufficient to saturate the urease activity of the bacterial flora of the upper gut.

The role of $\mathrm{H}$. pylori versus small bowel bacteria in urea catabolism is controversial. H. pylori have far greater urease activity than do other intestinal organisms, and studies in cirrhotic patients in east Asia found that eradication of $H$. pylori infection reduced the blood ammonia concentration while no such effect has been observed in Western countries. $^{22,23}$ The failure to find a clearly bimodal distribution rate of urea catabolism (determined by the presence or absence of $\mathrm{H}$. pylori) argues against an importance of $\mathrm{H}$. pylori in ammonia generation, and we will assume in this paper the small bowel, rather than the stomach, is the major site of urea catabolism.

The catabolism of $20 \%$ of the daily urea production would result in the deamination of roughly $61 \mu$ moles of urea/min. Given that urea contains two amines per molecule, the theoretical gut production of ammonia from urea is $122 \mu \mathrm{moles} / \mathrm{min}$, which extrapolates to $175 \mathrm{mmol}$ of ammonia per day, twice the observed rate that ammonia enters the portal circulation from all sources $(86 \mathrm{mmol} /$ day). Thus, it appears that at least $50 \%$ of the ammonia released in the gut from urea must be converted to some other nitrogen containing product by the luminal bacteria or intestinal tissue.

\section{Glutamine Catabolism}

Glutamine, the most abundant serum amino acid, plays an important role in a variety of amino transfer reactions. The intestinal tract has an unusual "appetite" for glutamine in that the gut extracts and catabolizes an appreciable fraction of the glutamine delivered via the blood flow. This extraction, quantitated via arterial-portal vein concentration differences, shows marked species variability - from 33\% extraction in the $\mathrm{rat}^{24}$ to values of $11 \%^{25}$ to $23 \%{ }^{15}$ in humans. Utilizing the lower value of $11 \%$, the roughly $0.6 \mathrm{mM}$ arterial blood glutamine concentration, 1000 $\mathrm{mL} / \mathrm{min}$ of portal blood flow, and two amines per glutamine molecule, the maximal potential ammonia production from this glutamine is relatively large:

$$
(0.11) \times(0.60 \mathrm{mM} / \mathrm{L}) \times(11 \mathrm{minute} 0 \times(1440 \mathrm{~min} / \text { day })
$$

$\times(2$ amines/glutamine $)=191 \mathrm{mmols} /$ day

a value far in excess of the previously calculated $86 \mathrm{mmol} /$ day of ammonia released into the portal blood from all sources. In contrast to urea catabolism in the gut that allows for a clear-cut quantitative estimate of intestinal ammonia release, ammonia derived from glutamine catabolism is more difficult to calculate. The initial step in glutamine metabolism is a glutaminase-catalyzed reaction resulting in the release of the amide nitrogen as ammonia and a glutamate, which can be further catabolized to: a) $\mathrm{CO}_{2}$ and a second ammonia or $\mathrm{b}$ ) converted to other amino acids, which would not result in the release of the second ammonia. A minimal estimate of the ammonia released via catabolism of glutamine extracted from the blood would be the initial $95 \mathrm{mmol} /$ day liberated via the action of glutaminase. (This value would be roughly doubled if the reported glutamine extraction of $23 \%$ had been utilized in the above calculations). Human studies have shown that venous-arterial decrease in glutamine concentration across the jejunum was about 4-fold greater than that of the colon, ${ }^{26}$ and glutaminase activity is appreciably greater in small intestinal versus colonic tissue. ${ }^{27}$ Thus, the majority of ammonia release from glutamine extracted from the blood probably occurs in the small bowel, similar to the situation with urea. Glutamine-derived ammonia could be much less susceptible to bacterial assimilation than is ureaderived ammonia since the former has to diffuse from the mucosa to the lumen to contact bacteria while urea is catabolized to ammonia within luminal bacteria.

A second source of glutamine-derived ammonia is the deamination of dietary glutamine during the absorption of amino acids released from dietary protein. Portal vein measurements in the rat indicate that about $65 \%$ of dietary glutamine is deaminated as it passes through the intestinal mucosa. ${ }^{28}$ This source of ammonia production explains the observation that ingestion of glutamine by cirrhotic patients resulted in a much greater increase in serum ammonia than was the case when glutamine was administered parenterally. ${ }^{29}$ Serum ammonia increased appreciably within 30 mins of oral glutamine administration, with a peak increase of $140 \mu \mathrm{gm} / \mathrm{dL}(82 \mu \mathrm{mol} / \mathrm{L})$ at 60 mins; thus, the ammonia production originated in the upper gut rather than the colon. Similarly, ingestion of a 20 g protein meal by cirrhotic subjects with extensive collateral circulation resulted in a significant increase in blood ammonia that peaked at $24 \mu \mathrm{gL} / \mathrm{dL}(15 \mu \mathrm{mol} / \mathrm{L})$ above baseline at 30 mins, returning to baseline by three hours. ${ }^{30}$ The early peak once again indicates that the bulk of this ammonia production occurred in the small bowel, presumable via the deamination of the glutamine content of the protein meal rather than bacterial deamination in the colon. Assuming 60\% portal-systemic shunting and a 150 $\mathrm{L}$ volume of ammonia distribution, we calculated that the observed post-meal blood ammonia increase would require 
the release of about $6 \mathrm{mmol}$ of ammonia from the protein meal. Deamination of $65 \%$ of the roughly $1.0 \mathrm{~g}$ of glutamine in the $20 \mathrm{~g}$ protein meal, would yield about $6 \mathrm{mmol}$ of ammonia. This study suggests that at least $24 \mathrm{mmol}$ of ammonia per day could be released from the glutamine content of the $80 \mathrm{~g}$ of protein ingested per day.

In a small controlled study, Cordoba and co-workers ${ }^{31}$ reported that the encephalopathy of cirrhotic patients was not aggravated by ingestion of a normal versus a low protein diet and fasting serum ammonia was comparable during the various feeding arms of the study. This finding should not be construed to indicate that protein feeding does not influence the serum ammonia level of patients with cirrhosis, which clearly rises substantially and rapidly with ingestion of a protein containing meal. This ammonia rise returns to baseline within three hours, hence, the finding of Cordoba, et.al. that protein intake did not influence the fasting ammonia level.

The concept that glutamine-derived ammonia could be a major source of ammonia is supported by multiple studies in germ-free animals. For example, germ-free dogs with surgically constructed portal-caval shunts had fasting and postblood meal serum ammonia concentrations comparable to those of conventional animals (with shunts). ${ }^{32}$ The blood ammonia in these germ-free dogs obviously was not originating from bacterial deamination of protein or urea, but rather from a source that does not require bacterial intermediation, e.g., glutamine deamination by the gut mucosa.

Liver glutamine metabolism is heterogeneous, with glutamine metabolized to $\mathrm{CO}_{2}$ and urea in the periportal hepatocytes, and glutamine synthesized from ammonia and glutamate in the perivenous hepatocytes. ${ }^{33-35}$ In the normal liver, this perivenous process accounts for about $50 \%$ of the liver ammonia clearance. ${ }^{8}$ These perivenous cells may be particularly sensitive to toxins and, for example, the hyperammonemia produced by carbon tetrachloride has been shown to result from the selective necrosis of these cells. ${ }^{36}$

\section{Bacterial Deamination Of Protein In Colon}

Fecal bacteria clearly have the ability to produce ammonia as evidenced by fecal ammonia concentrations that may reach levels of $30 \mathrm{mmol}, 1000$ times greater than serum concentrations of $30 \mu \mathrm{mol}$. The relatively enormous fecal ammonia concentration should not be construed to indicate that fecal excretion is an important means of excreting nitrogen since a $3 \mathrm{mM}$ ammonia concentration in roughly $100 \mathrm{~g}$ of fecal water excreted each day would account for only 3 mmoles of the 1000 mmoles of nitrogen eliminated from the body each day.

A yet to be identified "barrier" prevents the expected movement of this ammonia into the blood. For example, if there were only a $5 \%$ equilibration of ammonia between lumen $(30 \mathrm{mmol})$ and colonic blood flow, blood would leave the colon with a concentration of $1500 \mu \mathrm{M}$. A colonic blood flow of $300 \mathrm{~mL} / \mathrm{min}$ would deliver over 400 mmoles of ammonia per day to the portal blood, 5 times the total portal uptake of ammonia as determined by A-V difference measurements. Various mechanisms have been proposed to account for this ability of the colon to "store" ammonia including: 1) The permeabilty of the colonic mucosal to ammonia is very low with mucosal cells actively transporting ammonia to the lumen. 2) Very poor stirring of feces produces large unstirred layers that limit diffusion between the lumen and blood. 3) Fecal ammonia is concentrated within the colonic bacteria (which constitute $>50 \%$ of solid feces).

\section{Origin Of Portal Vein Ammonia}

There is a surprising lack of quantitative data to support the commonly held belief that bacterial catabolism of protein in the colon is the major source of gut and blood ammonia, and appreciable data to the contrary. The most direct quantitative evidence of where ammonia enters the portal blood is provided by $\mathrm{A}-\mathrm{V}$ differences in ammonia concentration across segments of bowel. Multiple such studies in animals indicated that the small bowel was the site of at least $50 \%$ of gut release of ammonia. An elegant study by Van Berlo et al in pigs measured A-V differences and blood flow of intestinal segments and concluded that $>75 \%$ of the ammonia of portal blood seemingly was derived from the small bowel. ${ }^{37}$ The only human study of A-V differences across the small bowel and colon (carried out at surgery) found $\mathrm{A}-\mathrm{V}$ increases in ammonia concentrations of $60 \mu \mathrm{m}, 33 \mu \mathrm{m}$ and $30 \mu \mathrm{m}$ in blood draining the jejunum, ileum and colon, respectively. ${ }^{26}$ While blood flow measurements were not obtained, the up to 5-fold greater blood flow to the small bowel versus the $\operatorname{colon}^{38}$ multiplied times the 2- fold greater A-V difference across the small bowel strongly suggests that the small bowel rather than the colon is the major site of gut ammonia delivery to portal blood.

The importance of the small bowel as a source of ammonia is further supported by several different indirect lines of reasoning. Measurements made on feces incubated ex-vivo showed that about $15 \%$ of the fecal nitrogen 
content was converted to ammonia over $24 \mathrm{hrs} .{ }^{39}$ About $2.5 \mathrm{~g} /$ day of nitrogen is delivered to the colon each day (ileostomy output measurements). A $24 \mathrm{hr}$ transit time through the colon would result in the daily release of $15 \%$ of the $2.5 \mathrm{~g}$ of nitrogen as ammonia, for a colonic production rate of $22 \mathrm{mmol} /$ day. If completely absorbed, this would provide only about $25 \%$ of the $85 \mathrm{mmols} /$ day of ammonia that is added to portal blood flow. The difference between the quantity of nitrogen entering and exiting the colon provides a maximal estimate of ammonia production, assuming all loss of nitrogen is via ammonia. (This assumption is questionable given that the colon has amino acid transporters, hence amino acids could be absorbed intact. $^{40}$ ) While measurements of nitrogen input and exit from the colon have not been obtained in the same subject, values obtained for ileostomy output and normal feces differ by perhaps $0.6 \mathrm{~g} / \mathrm{day}$, which is equivalent to about $37 \mathrm{mmol}$ of ammonia per day. A study in encephalopathic cirrhotic patients showed that colonic cleansing with a polyethylene glycol based solution (4 liters) reduced the blood ammonia concentration by only $26 \mu \mathrm{mol} / \mathrm{L}(19 \%)$, while a $93 \mu \mathrm{mol} / \mathrm{L}$ decline was observed with lactulose. ${ }^{41}$ This minimal (probably statisticallyinsignificant) reduction observed with colonic cleansing provides strong evidence against the concept that deamination of luminal protein by colonic bacteria is the major source of blood ammonia since colonic cleansing should reduce fecal protein and bacteria to a trivial fraction of their baseline concentrations. An example in this regard is our observation ${ }^{42}$ that polyethylene glycol cleansing of the colon dramatically reduced the production of $\mathrm{H}_{2}$ and $\mathrm{CH}_{4}$, two gases produced, like ammonia, from colonic bacterial metabolism of a luminal substrate (carbohydrate).

Lastly, it is not commonly recognized that the ammonia concentration of small bowel contents is several orders of magnitude greater than that of blood. For example, ammonia concentrations on the order of $2 \mathrm{mM}$ were measured in ileostomy effluent. ${ }^{43}$ It might be argued that that ileostomy outflow is not representative of intact small bowel contents; however, Minor-Williams and coworkers ${ }^{44}$ similarly found ammonia concentrations of at least $2 \mathrm{mM}$ in distal ileal fluid constantly aspirated from healthy controls. The expected absorption rate from this luminal ammonia concentration can be calculated from the data of Kettering and Summerskill ${ }^{45}$ who quantitated the rate of ammonia absorption during constant perfusion of the normal human small intestine. At an infusate concentation of $2.3 \mathrm{mM}$, ammonia was absorbed at a rate of about $0.50 \mathrm{mmol} / \mathrm{day} / \mathrm{cm}$ of intestine, ie, absorption of ammonia from $100 \mathrm{~cm}$ of ileum with the normal ammonia concentration of $2.3 \mathrm{mM}$ would deliver 50 of the $85 \mathrm{mmol} /$ day of ammonia calculated to enter portal blood each day.

\section{The Roles Of The Kidneys And Muscle In Ammonia Homeostasis}

The kidney produces large quantities of ammonia primarily via the deamination of glutamine, the bulk of which is used to alkinalize the urine while a fraction enters the blood. Based on A-V measurements across the kidney, a relatively constant amount of renal ammonia, roughly $22 \mathrm{mmol} /$ day, diffuses into the blood independent of total renal ammonia production, which is related to acid-base status. ${ }^{15}$ As discussed, this ammonia is delivered directly into the systemic blood (as opposed to portal blood) and does not undergo $70 \%$ hepatic first-pass metabolism as is the case with gut ammonia. Thus, in healthy subjects, a very sizable fraction of peripheral blood ammonia, about 44\% (22 mmol/day) originates in the kidney, while about $56 \%$ is of gut origin.

The role of muscle in ammonia homeostasis is complicated because it depends on both the blood ammonia concentration and the activity level of the muscle. At rest in normal subjects, there is a small muscle ammonia uptake of about $6 \mu \mathrm{m} / \mathrm{min}$, about $10 \%$ of the $60 \mu \mathrm{m} / \mathrm{min}$ rate of release of ammonia from the gut. In addition, this does not represent net ammonia uptake because most of this muscle ammonia $\mathrm{N}$ uptake is released as glutamine to the systemic circulation where it can potentially be converted back to ammonia. ${ }^{8}$ In contrast, exercising muscle can release large amounts of ammonia; with maximal exertion of a lower limb resulting in an ammonia production rate of $89 \mu \mathrm{mol} / \mathrm{min}$, a rate that exceeds the $60 \mu \mathrm{m} / \mathrm{min}$ rate of release from the gut. ${ }^{46}$

As the blood ammonia concentration increases, the muscle extraction also increases and can become an important factor in limiting the rise in blood ammonia in CLD. ${ }^{8}$ This is dramatically illustrated by the measurements of Snady and Lieber $^{47}$ of the arterial - antecubital vein forearm uptake. In normal resting subjects, there is no significant difference in the antecubital and arterial concentration, indicating negligible ammonia uptake. However, during marked hyperammonemia the A-V extraction across the forearm increases dramatically, to about $30 \%$. While this increase has been attributed to increased uptake by forearm muscle, this remarkable result requires further investigation. In normal subjects, only about $5 \%$ of the antecubital blood flow has perfused muscle - most of the blood perfuses skin $(25 \%)$ or passes through arterial- 
venous shunts $(53 \%){ }^{48}$ If this perfusion situation existed in cirrhosis, a muscle extraction of $100 \%$ of the ammonia would only account for about $1 / 6$ of the observed $30 \%$ extraction across the forearm. This indicates that hyperammonemia/portal hypertension must induce marked increase in forearm muscle perfusion and/or an increase in the ammonia metabolism of the non-muscular portion of the forearm.

The metabolism of ammonia by muscle raises several clinically relevant questions. First, in the past it was thought that reliable assessment of blood ammonia required analysis of arterial versus venous blood. The current reliance on antecubital vein measurements seemingly is based on the not well-studied assumption that a relatively constant percentage of ammonia is removed in the non-exercising forearm. Second, the release of ammonia by exercising muscle suggests that bedrest could minimize the systemic ammonia load. Lastly, to what extent does the low muscle mass of cirrhotic patients influence their serum ammonia level?

\section{Ammonia Balance In The Small Intestine}

As discussed previously, the small intestine appears to be the major intestinal site of deamination of urea and glutamine. Hence, we calculated the likely daily release of ammonia in the small bowel to be on the order of: a) $175 \mathrm{mmol} /$ day from the bacterial metabolism of urea, b) at least $95 \mathrm{mmol} /$ day from the metabolism of glutamine extracted from blood, and c) $24 \mathrm{mmol} /$ day from deamination of glutamine during the absorptive process - a total of $294 \mathrm{mmol} /$ day. Based on A-V differences for ammonia across the gut, only about $87 \mathrm{mmol} /$ day enters the portal vein, of which perhaps $25 \%$ or $22 \mathrm{mmol} /$ day seemingly is derived from the colon. Thus, only about $65 \mathrm{mmol} /$ day of the $294 \mathrm{mmol} /$ day of ammonia produced in the small bowel seemingly finds its way to portal blood. It follows that about $230 \mathrm{mmol} /$ day is metabolized to some other products (amino acids/protein) by the small bowel bacteria and/or the small bowel mucosa.

While it is commonly understood that intestinal bacteria can release ammonia from urea and protein, less well appreciated is the ability of bacteria to efficiently assimilate ammonia in the process of producing bacterial amino acids/protein. Culture studies have demonstrated that some intestinal bacteria utilize ammonia for protein synthesis in preference to culture media peptones and that bacteria proliferate when ammonia is the only source of nitrogen. ${ }^{49}$
The $230 \mathrm{mmol} /$ day of ammonia "disappearing" from the small bowel translates into about $2.5 \mathrm{~g}$ of nitrogen/day, a quantity roughly equal to the $2.5 \mathrm{~g}$ /day of nitrogen delivered daily from the small bowel to the colon. Support for the concept that the bacteria could play a major role in the disposal of small bowel ammonia is provided by MinorWilliams and coworkers ${ }^{44}$ who carried out a painstaking analysis of the nitrogen content of terminal ileal fluid constantly aspirated from healthy controls. Extrapolation of the results of this $8 \mathrm{hr}$ study to $24 \mathrm{hrs}$ indicates that about $2.8 \mathrm{~g}$ of protein nitrogen passed the terminal ileum each day of which $1.9 \mathrm{~g}$ or $135 \mathrm{mmol}$ was of bacterial origin. To the extent that this bacterial protein was synthesized from ammonia, such synthesis could account for the majority of the "disappearing" small bowel ammonia. Human tissue can utilize ammonia for synthesis of alanine and pyrimidines and the possibility that ammonia is utilized for synthetic reactions in the gut mucosa seemingly has not been investigated.

\section{Pathophysiology Of Hyperammonemia}

The vast majority of patients with hyperammonemia have some form of pathology involving the liver or the portal circulation, although excessive ammonia production from infection with urease containing organisms has been reported. Disease of the liver that increases blood ammonia generally takes one of three forms: a) chronic liver disease (CLD) resulting from cirrhosis; b) acute hepatic necrosis; and c) defects in the urea cycle that are congenital and/or drug related. The pathophysiology of the ammonia handling differs for these three categories of liver disease - our discussion will be limited to CLD, the most common cause of hyperammonemia and the condition in which lactulose and rifaximin are most often employed.

It is not commonly recognized that the hyperammonemia of CLD usually can be accounted for simply by the existence of portal-systemic shunting and there is no need to implicate either increased ammonia production or hepatic cell dysfunction. This shunting elevates blood ammonia concentrations by two mechanisms: a) circumvention of first-pass metabolism of ammonia in the liver and b) decreased blood flow to the liver that slows the hepatic removal of the ammonia that has reached peripheral circulation. Assuming that all other aspects of ammonia handling are normal (including hepatic cell function), we 
calculated that as shunting increases from 0 to $100 \%$ of portal blood flow, the blood ammonia would increase from $30 \mu \mathrm{M}$ to $250 \mu \mathrm{M}^{8}{ }^{8}$ The roughly $65 \%$ shunting of portal blood commonly observed in advanced CLD (Child-Pugh class C) would result in a predicted systemic ammonia concentration of $107 \mu \mathrm{M}$. Serum ammonia values in excess of $250 \mu \mathrm{M}$ indicates that the ability of the liver to convert ammonia to urea is impaired, as occurs with defects in the urea cycle enzyme system and acute hepatic necrosis.

Several mechanisms could mitigate the ammonia levels predicted to occur solely on the basis of shunting. First, our modeling assumed that total hepatic blood flow would decrease pari passu with the rate that blood was shunted to the peripheral circulation. In fact, modest increases in hepatic artery flow may partially compensate for the decreased flow from the portal system. ${ }^{50}$ In addition there is the previously discussed ability of muscle to convert ammonia to glutamine in hyperammonemic states. In fact, A-V difference measurements have shown that in CLD with severe hyperammonemia, serum ammonia removal by the muscle approaches that of the liver.

Surprisingly, the TIPSS procedure does not result in increased serum ammonia concentrations despite the nearly $100 \%$ shunting induced by this manipulation. ${ }^{51}$ The extensive studies of Damink et al $^{52}$ utilizing measurements of $\mathrm{A}-\mathrm{V}$ differences of ammonia across the kidney demonstrates the important, but commonly overlooked, role of the kidney in the hyperammonemia of CLD. Measurements made just prior to the performance of TIPPS procedure (ie, in patients with appreciable portal hypertension) showed the kidneys were releasing ammonia into the systemic blood at a rate of about $49 \mathrm{mmol} /$ day, twice the normal rate. This rate fell to normal almost immediately after performance of the TIPSS; presumably the decrease in portal pressure resulting from the TIPSS somehow normalized the renal release of ammonia into the blood, thus, balancing the increased ammonia delivery that would result from the increased shunting. Damink's ${ }^{53}$ studies also provide an insight into the hyperammonemia commonly observed with gastrointestinal bleeding. The gut and renal release of ammonia were measured in cirrhotic patients after intra-gastric instillation of a mixture of amino acids simulating the composition of hemoglobin. This study, a true tour de force, involved measurements of blood flow and A-V differences for ammonia across both the gut and kidney. The surprising result was that ammonia release by the kidney, not the gut, accounted for the hyperammonemia observed in this simulated GI bleeding experiment. An effect on renal ammonia production has been proposed to explain the $40 \%$ reduction in serum ammonia observed in well-compensated cirrhotic patients following a rapid infusion of one liter of saline. ${ }^{54}$ Such an infusion has been shown to acutely increase the ammonia output into the urine, and the authors postulate that a commensurate decline in renal ammonia output into the blood accounts for the decline in serum ammonia. This rehydration effect possibly could explain why elevated serum ammonia levels in sick pediatric patients without liver disease often rapidly normalized without specific ammonia lowering therapy - a phenomenon that was attributed to laboratory error by the authors. ${ }^{55}$

\section{Mechanisms Of Action Of Lactulose And Rifaximin \\ Lactulose}

Lactulose is a disaccharide consisting of galactose linked to fructose by a bond that is undigestible by human enzymes but hydrolyzable by intestinal bacteria. Since the intact disaccharide is non-absorbable, this sugar tends to pass through the small bowel, where it is rapidly fermented by the colonic flora. The result is acidification of colonic contents and variable diarrhea, depending upon lactulose dosage. In 1966 Bircher et $\mathrm{al}^{56}$ described the first use of lactulose to treat hepatic encephalopathy in CLD - the encephalopathy of two of three patients appeared to respond in an uncontrolled study. The stated rationale was the belief that a colonic acidic acid environment reduces the bacterial production of putative neuro toxins, one of which is ammonia. Lactulose was used sparingly until publication of a landmark study by Conn and co-workers ${ }^{57}$ in 1977 showing that lactulose was at least as effective as neomycin/sorbitol combination in the alleviation of hepatic encephalopathy, and the approximately $30 \%$ reduction in ammonia with lactulose was slightly, but significantly greater than observed with neomycin/sorbitol. (This study assumed that neomycin, the commonly employed treatment for hepatic encephalopathy at the time, was effective; sorbitol, considered to have no influence on encephalopathy, was used to blind for the liquid nature of lactulose). Subsequently, lactulose became and has remained the mainstay of treatment of hepatic encephalopathy in CLD. Multiple controlled trials have shown that lactulose induces a roughly $30 \%$ reduction in serum ammonia, and a 2016 Cochran Systematic Review 
of 38 controlled trials concluded that lactulose administration is associated with a roughly $40 \%$ reduction in both mortality and frequency of severe bouts of encephalopathy in CLD. ${ }^{5}$

Despite abundant research over the past 50 years, the mechanism(s) via which lactulose reduces serum ammonia concentration remains controversial. Lactulose is fermented by the colonic flora with resultant release of short chain fatty acids and acidification of feces. The fermentation has been assumed to explain the ammonia-lowering ability of lactulose. In vivo studies using a $\mathrm{pH}$ sensitive capsule showed that the usual lactulose dosage of 30-40 g/ day acidified only the right colon; larger doses are required to acidify the distal colon. ${ }^{58}$ Initially it was proposed that this acid environment reduced serum ammonia via the inhibition of non-ionic diffusion of ammonia from colonic lumen to blood, a concept refuted by the negligible quantity of ammonia excreted in feces (with or without lactulose treatment). A second acid-related postulate was based on in vitro fecal incubation studies demonstrating that ammonia production from urea or protein is markedly inhibited at a fecal $\mathrm{pH}$ of $<5.0$ or less, a level of acidification observed in the right colon during lactulose ingestion. ${ }^{39}$ Of particular interest was the observation that the addition of lactulose to the homogenate not only inhibited ammonia release, but resulted in a sharp fall in the initial ammonia concentration to undetectable levels, ie, lactulose stimulated the removal of ammonia from the homogenate. Presumably, this finding reflects the ability of lactulose to enhance the bacterial utilization of ammonia for amino acid synthesis.

The relevance of colonic acidification to the serum ammonia reduction observed with lactulose requires that the colon (pre- lactulose) be a major source of serum ammonia. As discussed, A-V difference measurement along with other data suggest that the bulk of the ammonia produced in the gut arises from the small bowel rather than the colon. If this is the case, some action of lactulose in the small bowel would be required to produce the sizable reductions in serum ammonia observed with this disaccharide. A very informative study in this regard is the previously cited trial of Rahimi et $\mathrm{al}^{41}$ who carried out a randomized comparison of the efficacy of lactulose (approximately $60 \mathrm{gm} /$ day) versus a polyethylene glycol (PEG) based electrolyte solution (4 liters) in the treatment of overt hepatic encephalopathy. Compared to lactulose, the PEG solution produced far more laxation and more rapid amelioration of hepatic encephalopathy than did lactulose. However, lactulose was associated with a much greater reduction of blood ammonia concentration (93 $\mu \mathrm{mol} / \mathrm{L})$ than with the colonic cleansing solution (26 $\mu \mathrm{mol} / \mathrm{L})$. Several conclusions concerning ammonia may be drawn from this study: a) since the ultimate in laxation, colonic cleansing, had a minimal effect on blood ammonia, the ammonia reducing property of lactulose cannot be attributed to laxation; b) the clinical efficacy of colonic cleansing despite the minimal decline in serum ammonia suggests that toxins produced in the colon other than ammonia play a major role in the pathogenesis of hepatic encephalopathy; and c) most important from the standpoint of ammonia physiology is that the lactulose seemingly exerts its activity primarily in the small rather than large bowel. As discussed, the last conclusion is based on the concept that the colonic cleansing solution should very effectively flush out both luminal protein substrate and deaminating bacteria, reducing colonic ammonia production from luminal protein to negligible levels. The much greater ammonia lowering capacity of lactulose versus the cleansing solution therefore suggests that lactulose must have an extra-colonic effect, presumably reducing the rate of absorption of ammonia from the small bowel. While it might be assumed that the beneficial effect of lactulose enemas on hepatic encephalopathy ${ }^{59}$ supports a colonic origin of ammonia, these enemas did not induce a significant reduction in serum ammonia.

If the small intestine, rather than the colon, is the primary source of systemic ammonia, the obvious question is how lactulose alters ammonia physiology in the small bowel. The answer possibly is related to the finding that lactulose ingestion markedly increased fecal nitrogen excretion by $18 \mathrm{mg} / \mathrm{kg} /$ day or $1.3 \mathrm{~g} /$ day (93 mmol/day) for a $70 \mathrm{~kg}$ subject. ${ }^{60}$ Presumably this increased fecal nitrogen requires increased delivery of nitrogen from the ileum to the colon in the form of a) non-absorbed dietary amino acids/protein or b) bacterial amino acids/protein. The former "wastes" a fraction of the dietary protein in the diet - ie simulates a reduced oral protein intake. However, the increase in fecal nitrogen observed with lactulose is equivalent to only about $8 \mathrm{~g}$ of protein or about $10 \%$ of dietary intake. Given that major variations in oral protein intake in a controlled trial had no discernible effect on basal serum ammonia concentration of cirrhotic patients, ${ }^{31}$ a $10 \%$ reduction in protein intake seemingly cannot explain the ability of lactulose to reduce serum ammonia. On the other hand, the formation of $8 \mathrm{gm}$ of bacterial protein in the small bowel could have major 
impact on the serum ammonia level if a major fraction of this protein was synthesized from intestinal ammonia. Based on our previous discussion of ammonia physiology, it is tempting to speculate the following scenario. Very appreciable quantities of ammonia are released in the small bowel lumen from the bacterial catabolism of urea and the small bowel mucosal deamination of glutamine. The more efficiently this ammonia is locally converted to bacterial amino acids/protein, the less is available for absorption. A unique aspect of lactulose relative to other cathartics is that lactulose is readily fermented by gut bacteria, providing an energy source to enhance bacterial proliferation. This proliferation requires a nitrogen source for the synthesis of amino acids and protein, and to the extent that ammonia is used for this purpose, the bacterial uptake of ammonia will be increased. In support of this concept is the finding that lactulose did not increase fecal nitrogen in germ-free rats (as was the case in conventional rats) indicating that the intestinal flora play a role in the increased delivery of ammonia to the colon. ${ }^{61}$ In addition, Vince and coworkers ${ }^{39}$ found that addition of lactulose to fecal incubates not only slowed the release of ammonia but, in addition, transiently reduced the initial fecal ammonia concentration of the homogenate to very low levels, indicating that lactulose can bring about uptake of preformed ammonia, presumably via the conversion to bacterial protein. The extent to which ammonia uptake accounts for the additional $8 \mathrm{~g}$ of protein $(93 \mathrm{mmol}$ of nitrogen) entering the colon with lactulose therapy is unknown. However, if only $30 \%$ of this nitrogen were derived from ammonia, portal blood ammonia uptake would be reduced by $31 \mathrm{mmol} /$ day $(50 \%$ of the normal ammonia contribution of the gut to portal blood), an alteration that would appreciably reduce serum ammonia levels in patients shunting most of their portal flow.

As discussed previously, since glutamine deamination occurs in the small bowel mucosa, much of the ammonia released from this reaction presumably will enter the blood with only a small fraction being available for bacterial uptake in the gut. Thus, lactulose might be expected to have a minor effect on ammonia released from glutamine. However, lactitol administration halved the $76 \mu \mathrm{M}$ increase in serum ammonia of cirrhotic patients observed after ingestion of $20 \mathrm{~g}$ of glutamine. ${ }^{29}$ Animal studies showed that lactulose treatment was associated with a roughly $50 \%$ reduction in the gut extraction of glutamine in pigs ${ }^{37}$ and also reduced the rate that ammonia was released from glutamine by rat intestinal mucosal cells. ${ }^{62}$ Thus, by some unknown mechanism it appears that lactulose reduces the glutaminase activity of the small bowel with a resultant reduction of glutamine-related ammonia release.

\section{Rifaximin}

Over 60 years ago, oral administration of neomycin, an antibiotic with activity against a wide spectrum of enteric organisms, was shown to both reduce the serum ammonia level and the severity of hepatic encephalopathy in patients with CLD. While very poorly absorbable, chronic usage of this antibiotic was limited by severe ototoxicity resulting from its limited absorption. Rifaximin, a totally non-absorbable analogue of rifampin, also has activity against a wide variety of enteric bacteria and multiple studies beginning about 30 years ago have shown that this antibiotic improves hepatic encephalopathy and reduces serum ammonia concentration by roughly $50 \%$. There has been surprisingly little study of the how rifaximin/neomycin reduce serum ammonia levels, although these antibiotics are commonly assumed to inhibit the deamination of protein in the colon. If this were the case, one would expect a concomitant increase in the quantity of nitrogen excreted in feces. Surprisingly, the co-administration of neomycin with lactulose actually modestly reduced the fecal nitrogen excretion observed with lactulose alone. ${ }^{63}$ Thus, neomycin seemingly did not inhibit ammonia release in the colon, but rather may have "interfered" with the lactulose-induced bacterial uptake of ammonia in the small bowel (discussed previously). Additonal studies clearly are needed to determine exactly how/if the antibacterial action of antibiotics translates into decreased serum ammonia. Of interest are studies suggesting that these antibiotics inhibit the intestinal mucosal metabolism of ammonia release from the catabolism of glutamine, a non-bacterially mediated reaction. For example, rifaximin treatment brought about a $50 \%$ reductions in serum ammonia of germ-free rats, which appeared to be related to the observed $50 \%$ reduction in intestinal glutaminase activity ${ }^{64}$ and neomycin reduced the activity of glutaminase and ammonia release of rat intestinal segments. ${ }^{62,65}$

\section{Combined Therapy With Lactulose And Rifaximin}

As discussed at length, lactulose seemingly reduces serum ammonia by enhancing small bowel bacterial proliferation with the uptake of ammonia, while rifaximin and neomycin presumably inhibit the intestinal flora. Thus, these drugs might antagonize each other's action when used in 
combination. No such antagonism has been observed in clinical studies and combination therapy is the norm in the treatment of hepatic encephalopathy in CLD. The only study of the interaction of these two drugs with regard to serum ammonia is the study of Pirotte et $\mathrm{al}^{66}$ who measured the decline of blood ammonia following administration of lactulose or neomycin individually and in combination. Serial measurements in nine CLD patients with stable blood ammonia elevations showed that lactulose and neomycin used individually resulted in minor reductions in the fasting ammonia concentration of $14 \%$ and $18 \%$, respectively. Surprisingly, in each of the 9 patients, combination therapy with the two drugs had more than an additive effect on ammonia reduction, with an average 59\% decline in fasting ammonia. While the explanation of this synergy is not clear, more inexplicable was the authors' finding of a similar scenario when the peak rise in blood ammonia was determined in cirrhotic patients ingesting $64 \mathrm{mmol}$ of ammonia in the form of $5 \mathrm{~g}$ of ammonium acetate. The peak ammonia concentration was observed within 30 mins in all studies, indicating that the majority of ammonia was absorbed from the stomach or upper small bowel. In the control situation (no lactulose nor neomycin) serum ammonia peaked at $166 \mu \mathrm{M}$ above baseline. As expected, roughly similar peak increases were observed when the ammonia load was administered during therapy with either lactulose or neomycin since neither drug would be expected to materially influence the very rapid absorption of this large ammonia load from the upper gut. The unique finding was that when ammonium acetate was administered during combination therapy with lactulose and rifaximin, blood ammonia peaked at only $51 \mu \mathrm{M}$, about $33 \%$ of the increase observed with either drug alone or in the control state. We are unaware of any mechanism involved in ammonia homeostasis that would provide a plausible explanation for how the combination of lactulose and neomycin could so dramatically reduce the quantity of ingested ammonia reaching the peripheral circulation - an effect that requires "sequestration" of about $40 \mathrm{mmol}$ of ammonia over roughly 30 mins in the upper small bowel. The authors provide no explanation for this observation and, surprisingly, this paper has received very little attention in the ammonia literature. If the claim that lactulose plus neomycin appreciably reduces ammonia absorption from the upper gut is reproducible, elucidation of the responsible mechanism would provide novel insights into ammonia physiology.

\section{Role Of Ammonia In The Encephalopathy Of CLD}

Studies in otherwise healthy animals have shown that infusions of ammonia can induce mental and EEG alterations typical of hepatic encephalopathy. In one such study, ammonia was infused into control rabbits over a $10 \mathrm{hr}$ period to simulate the blood ammonia concentrations observed in paired rabbits with acute hepatic necrosis, using EEG alterations to assess the severity of encephalopathy. While encephalopathy was observed with the ammonia infusion, the severity was appreciably less than was observed in the hepatic necrosis animals, despite similar ammonia concentrations $(>200 \mu \mathrm{M}$ for the majority of the study). This study demonstrates that blood ammonia concentrations $>200 \mu \mathrm{M}$ can induce encephalopathy in otherwise healthy animals, however, factors in addition to ammonia clearly played a role in the encephalopathy of acute hepatic necrosis.

The belief that ammonia plays an important role in the encephalopathy of CLD is largely based on extrapolation of findings at very high serum ammonia to the more modestly elevated ammonias observed in CLD. Such extrapolation appears flawed since multiple studies ${ }^{67-69}$ have shown a very poor correlation between the grade of encephalopathy and venous or arterial ammonia measurements. The largest study ${ }^{68}$ of 121 patients with CLD showed roughly similar venous or arterial ammonia concentrations in Grade 0, 1 and 2 encephalopathy; the concentrations rose appreciably with Grade 3 encephalopathy, but about $50 \%$ of values were still within the range of patients with no encephalopathy. Only with Grade 4 encephalopathy (coma) did ammonia concentrations clearly separate from those without encephalopathy. While one might be tempted to conclude that the high ammonia was responsible for severe encephalopathy, Nicolao ${ }^{67}$ observed that a decline in a patient's encephalopathy from grade 3-4 to Grade 0 often was not associated with a decline in blood ammonia. Thus, factors other than ammonia are responsible for the encephalopathy of CLD patients, and the current clinical dogma is that ammonia measurements are of little value in the assessment of encephalopathy of CLD patients. ${ }^{70,71}$

\section{Conclusions Regarding The Mechanism(s) Of Action Of Lactulose And Rifaximin In Hepatic Encephalopathy}

In the present era when drug activity is understood at the molecular level, lactulose and rifaximin are outliers - their 
usage is based upon empirical evidence that they reduce blood ammonia and the severity of hepatic encephalopathy in CLD, rather than an understanding of their mechanism of action. Investigation of how these drugs reduce encephalopathy primarily has been directed to study of how they might reduce ammonia release from the gut, a topic discussed at length in this paper. However, there is abundant evidence that ammonia plays a limited role in hepatic encephalopathy of CLD; thus, the attention directed to the influence of lactulose and rifaximin on ammonia production seemingly has been the proverbial search for the lost key under the lamppost. Presumably, the reduced first pass clearance of a yet to be identified colonic bacterial metabolites is responsible for the encephalopathy of patients with CLD, and the beneficial activity of lactulose and rifaximin reflects the ability of these agents to inhibit the production of these putative toxins. Determining how lactulose and rifaximin inhibit the production of these metabolites hopefully will be less complicated than the unraveling of how these drugs inhibit ammonia release.

\section{Disclosure}

The authors report no conflicts of interest in this work.

\section{References}

1. Mas A, Rodes J, Sunyer L, et al. Comparison of rifaximin and lactitol in the treatment of acute hepatic encephalopathy: results of a randomized, double-blind, double-dummy, controlled clinical trial. $J$ Hepatol. 2003;38(1):51-58. doi:10.1016/s0168-8278(02)00350-1

2. Miglio F, Valpiani D, Rossellini SR, Ferrieri A. Rifaximin, a nonabsorbable rifamycin, for the treatment of hepatic encephalopathy. A double-blind, randomised trial. Curr Med Res Opin. 1997;13(10):593601. doi:10.1185/03007999709113333

3. Paik YH, Lee KS, Han $\mathrm{KH}$, et al. Comparison of rifaximin and lactulose for the treatment of hepatic encephalopathy: a prospective randomized study. Yonsei Med J. 2005;46(3):399-407. doi:10.3349/ ymj.2005.46.3.399

4. Pedretti G, Calzetti C, Missale G, Fiaccadori F. Rifaximin versus neomycin on hyperammoniemia in chronic portal systemic encephalopathy of cirrhotics. A double-blind, randomized trial. Ital $J$ Gastroenterol. 1991;23(4):175-178.

5. Gluud LL, Vilstrup H, Morgan MY. Non-absorbable disaccharides versus placebo/no intervention and lactulose versus lactitol for the prevention and treatment of hepatic encephalopathy in people with cirrhosis. Cochrane Database Syst Rev. 2016;(5):CD003044.

6. De Las Heras J, Aldamiz-Echevarria L, Martinez-Chantar ML, Delgado TC. An update on the use of benzoate, phenylacetate and phenylbutyrate ammonia scavengers for interrogating and modifying liver nitrogen metabolism and its implications in urea cycle disorders and liver disease. Expert Opin Drug Metab Toxicol. 2017;13(4):439448. doi:10.1080/17425255.2017.1262843

7. Rockey DC, Vierling JM, Mantry P, et al. Randomized, double-blind, controlled study of glycerol phenylbutyrate in hepatic encephalopathy. Hepatology. 2014;59(3):1073-1083. doi:10.1002/hep.26611

8. Levitt DG, Levitt MD. A model of blood-ammonia homeostasis based on a quantitative analysis of nitrogen metabolism in the multiple organs involved in the production, catabolism, and excretion of ammonia in humans. Clin Exp Gastroenterol. 2018;11::193-215. doi:10.2147/CEG.S160921
9. Cooper AJ, Plum F. Biochemistry and physiology of brain ammonia. Physiol Rev. 1987;67(2):440-519. doi:10.1152/physrev.1987.67.2.440

10. Rosenspire KC, Schwaiger M, Mangner TJ, Hutchins GD, Sutorik A, Kuhl DE. Metabolic fate of [13N]ammonia in human and canine blood. J Nucl Med. 1990;31(2):163-167.

11. Weiner ID, Verlander JW. Molecular physiology of the Rh ammonia transport proteins. Curr Opin Nephrol Hypertens. 2010;19(5):471477. doi:10.1097/MNH.0b013e32833bfa4e

12. Levitt DG. PKQuest Java: free, interactive physiologically based pharmacokinetic software package and tutorial. BMC Res Notes. 2009;2:158. doi:10.1186/1756-0500-2-158

13. Rudman D, DiFulco TJ, Galambos JT, Smith RB 3rd, Salam AA, Warren WD. Maximal rates of excretion and synthesis of urea in normal and cirrhotic subjects. J Clin Invest. 1973;52(9):2241-2249. doi:10.1172/JCI107410

14. McDermott WV, Adams RD, Riddell AG. Ammonia metabolism in man. Ann Surg. 1954;140(4):539-556. doi:10.1097/00000658-19541000000010

15. van de Poll MC, Ligthart-Melis GC, Olde Damink SW, et al. The gut does not contribute to systemic ammonia release in humans without portosystemic shunting. Am J Physiol Gastrointest Liver Physiol. 2008;295(4):G760-G765. doi:10.1152/ajpgi.00333.2007

16. Jackson AA, Picou D, Landman J. The non-invasive measurement of urea kinetics in normal man by a constant infusion of $15 \mathrm{~N} 15 \mathrm{~N}$-urea. Hum Nutr Clin Nutr. 1984;38(5):339-354.

17. Walser M, Bodenlos LJ. Urea metabolism in man. J Clin Invest. 1959;38:1617-1626. doi:10.1172/JCI103940

18. Wrong OM, Vince A. Urea and ammonia metabolism in the human large intestine. Proc Nutr Soc. 1984;43(1):77-86. doi:10.1079/ pns 19840030

19. Nance FC, Kaufman HJ, Kline DG. Role of urea in the hyperammonemia of germ-free Eck fistula dogs. Gastroenterology. 1974;66(1):108-112.

20. Walser M. Urea metabolism in chronic renal failure. J Clin Invest. 1974;53(5):1385-1392. doi:10.1172/JCI107687

21. Ewe K, Summerskill WH. Transfer of Ammonia in the Human Jejunum. J Lab Clin Med. 1965;65:839-847.

22. Chakrabarti P, Zullo A, Hassan C, et al. Helicobacter pylori, gastric juice, and arterial ammonia levels in patients with cirrhosis. $J$ Clin Gastroenterol. 2002;34(5):578-581. doi:10.1097/00004836-20020500000020

23. Chen SJ, Wang LJ, Zhu Q, Cai JT, Chen T, Si JM. Effect of H pylori infection and its eradication on hyperammo-nemia and hepatic encephalopathy in cirrhotic patients. World J Gastroenterol. 2008;14 (12):1914-1918. doi:10.3748/wjg.14.1914

24. Windmueller HG, Spaeth AE. Uptake and metabolism of plasma glutamine by the small intestine. J Biol Chem. 1974;249(16):50705079.

25. Olde Damink SW, Jalan R, Redhead DN, Hayes PC, Deutz NE, Soeters PB. Interorgan ammonia and amino acid metabolism in metabolically stable patients with cirrhosis and a TIPSS. Hepatology. 2002;36(5):1163-1171. doi:10.1053/jhep.2002.36497

26. van der Hulst RR, von Meyenfeldt MF, Deutz NE, Soeters PB. Glutamine extraction by the gut is reduced in depleted [corrected] patients with gastrointestinal cancer. Ann Surg. 1997;225(1):112-121. doi:10.1097/00000658-199701000-00013

27. James LA, Lunn PG, Elia M. Glutamine metabolism in the gastrointestinal tract of the rat assess by the relative activities of glutaminase (EC 3.5.1.2) and glutamine synthetase (EC 6.3.1.2). Br J Nutr. 1998;79(4):365-372. doi:10.1079/bjn19980061

28. Battezzati A, Brillon DJ, Matthews DE. Oxidation of glutamic acid by the splanchnic bed in humans. Am J Physiol. 1995;269(2 Pt 1): E269-E276. doi:10.1152/ajpendo.1995.269.2.E269

29. Masini A, Efrati C, Merli M, et al. Effect of lactitol on blood ammonia response to oral glutamine challenge in cirrhotic patients: evidence for an effect of nonabsorbable disaccharides on small intestine ammonia generation. Am J Gastroenterol. 1999;94(11):33233327. doi:10.1111/j.1572-0241.1999.01546.x 
30. Kabadi UM, Eisenstein AB, Konda J. Elevated plasma ammonia level in hepatic cirrhosis: role of glucagon. Gastroenterology. 1985;88(3):750-756. doi:10.1016/0016-5085(85)90146-5

31. Cordoba J, Lopez-Hellin J, Planas M, et al. Normal protein diet for episodic hepatic encephalopathy: results of a randomized study. $J$ Hepatol. 2004;41(1):38-43. doi:10.1016/j.jhep.2004.03.023

32. Nance FC, Batson RC, Kline DG. Ammonia production in germ-free Eck fistula dogs. Surgery. 1971;70(2):169-174.

33. Gebhardt R, Mecke D. Heterogeneous distribution of glutamine synthetase among rat liver parenchymal cells in situ and in primary culture. EMBO J. 1983;2(4):567-570.

34. Haussinger D. Nitrogen metabolism in liver: structural and functional organization and physiological relevance. Biochem J. 1990;267 (2):281-290. doi:10.1042/bj2670281

35. Stoll B, Hussinger D. Functional hepatocyte heterogeneity. Vascular 2-oxoglutarate is almost exclusively taken up by perivenous, glutamine-synthetase-containing hepatocytes. Eur J Biochem. 1989;181 (3):709-716. doi:10.1111/j.1432-1033.1989.tb14781.x

36. Haussinger D, Gerok W. Hepatocyte heterogeneity in ammonia metabolism: impairment of glutamine synthesis in $\mathrm{CCl} 4$ induced liver cell necrosis with no effect on urea synthesis. Chem Biol Interact. 1984;48(2):191-194. doi:10.1016/0009-2797(84)90120-0

37. van Berlo CL, van Leeuwen PA, Soeters PB. Porcine intestinal ammonia liberation. Influence of food intake, lactulose and neomycin treatment. $J$ Hepatol. 1988;7(2):250-257. doi:10.1016/s0168-8278(88)80489-6

38. Goodhead B. Distribution of blood flow in various selected areas of small and large intestine in the dog. Am J Physiol. 1969;217(3):835837. doi:10.1152/ajplegacy.1969.217.3.835

39. Vince A, Killingley M, Wrong OM. Effect of lactulose on ammonia production in a fecal incubation system. Gastroenterology. 1978;74 (3):544-549.

40. van der Wielen N, Moughan PJ, Mensink M. Amino acid absorption in the large intestine of humans and porcine models. J Nutr. 2017;147 (8):1493-1498. doi:10.3945/jn.117.248187

41. Rahimi RS, Singal AG, Cuthbert JA, Rockey DC. Lactulose vs polyethylene glycol 3350-electrolyte solution for treatment of overt hepatic encephalopathy: the HELP randomized clinical trial. JAMA Intern Med. 2014;174(11):1727-1733. doi:10.1001/jamainternmed.2014.4746

42. Strocchi A, Bond JH, Ellis C, Levitt MD. Colonic concentrations of hydrogen and methane following colonoscopic preparation with an oral lavage solution. Gastrointest Endosc. 1990;36(6):580-582. doi:10.1016/s0016-5107(90)71168-6

43. Chacko A, Cummings JH. Nitrogen losses from the human small bowel: obligatory losses and the effect of physical form of food. Gut 1988;29(6):809-815. doi:10.1136/gut.29.6.809

44. Miner-Williams W, Deglaire A, Benamouzig R, Fuller MF, Tome D, Moughan PJ. Endogenous proteins in terminal ileal digesta of adult subjects fed a casein-based diet. Am J Clin Nutr. 2012;96(3):508515. doi:10.3945/ajcn.111.033472

45. Kettering RF, Summerskill WH. Comparison of effects of $\mathrm{pH}$ and concentration gradients on ammonia transport in the human jejunum. Medicine (Baltimore). 1967;46(2):91-96. doi:10.1097/00005792196703000-00003

46. Banister EW, Cameron BJ. Exercise-induced hyperammonemia: peripheral and central effects. Int J Sports Med. 1990;11 Suppl 2:S129S142. doi:10.1055/s-2007-1024864

47. Snady H, Lieber CS. Venous, arterial, and arterialized-venous blood ammonia levels and their relationship to hepatic encephalopathy after propranolol. Am J Gastroenterol. 1988;83(3):249-255.

48. Levitt DG. Physiologically based pharmacokinetic modeling of arterial - antecubital vein concentration difference. BMC Clin Pharmacol. 2004;4:2. doi:10.1186/1472-6904-4-2

49. Magasanik B. The regulation of nitrogen utilization in enteric bacteria. J Cell Biochem. 1993;51(1):34-40. doi:10.1002/jcb.240510108
50. Iwao T, Toyonaga A, Shigemori $\mathrm{H}$, et al. Hepatic artery hemodynamic responsiveness to altered portal blood flow in normal and cirrhotic livers. Radiology. 1996;200(3):793-798. doi:10.1148/ radiology.200.3.8756933

51. Olde Damink SW, Dejong CH, Deutz NE, et al. Kidney plays a major role in ammonia homeostasis after portasystemic shunting in patients with cirrhosis. Am J Physiol Gastrointest Liver Physiol. 2006;291(2): G189-G194. doi:10.1152/ajpgi.00165.2005

52. Olde Damink SW, Deutz NE, Dejong CH, Soeters PB, Jalan R. Interorgan ammonia metabolism in liver failure. Neurochem Int. 2002;41(2-3):177-188. doi:10.1016/s0197-0186(02)00040-2

53. Olde Damink SW, Jalan R, Deutz NE, et al. The kidney plays a major role in the hyperammonemia seen after simulated or actual GI bleeding in patients with cirrhosis. Hepatology. 2003;37(6):1277-1285. doi:10.1053/jhep.2003.50221

54. Jalan R, Kapoor D. Enhanced renal ammonia excretion following volume expansion in patients with well compensated cirrhosis of the liver. Gut. 2003;52(7):1041-1045. doi:10.1136/gut.52.7.1041

55. Maranda B, Cousineau J, Allard P, Lambert M. False positives in plasma ammonia measurement and their clinical impact in a pediatric population. Clin Biochem. 2007;40(8):531-535. doi:10.1016/j. clinbiochem.2007.01.024

56. Bircher J, Muller J, Guggenheim P, Haemmerli UP. Treatment of chronic portal-systemic encephalopathy with lactulose. Lancet. 1966;1(7443):890-892. doi:10.1016/s0140-6736(66)91573-x

57. Conn HO, Leevy CM, Vlahcevic ZR, et al. Comparison of lactulose and neomycin in the treatment of chronic portal-systemic encephalopathy. A double blind controlled trial. Gastroenterology. 1977;72(4 Pt 1):573-583.

58. Bown RL, Gibson JA, Sladen GE, Hicks B, Dawson AM. Effects of lactulose and other laxatives on ileal and colonic $\mathrm{pH}$ as measured by a radiotelemetry device. Gut. 1974;15(12):999-1004. doi:10.1136/ gut.15.12.999

59. Uribe M, Campollo O, Vargas F, et al. Acidifying enemas (lactitol and lactose) vs. nonacidifying enemas (tap water) to treat acute portal-systemic encephalopathy: a double-blind, randomized clinical trial. Hepatology. 1987;7(4):639-643. doi:10.1002/hep.1840070404

60. Weber FL Jr. The effect of lactulose on urea metabolism and nitrogen excretion in cirrhotic patients. Gastroenterology. 1979;77(3):518-523.

61. Bird SP, Hewitt D, Ratcliffe B, Gurr MI. Effects of lactulose and lactitol on protein digestion and metabolism in conventional and germ free animal models: relevance of the results to their use in the treatment of portosystemic encephalopathy. Gut. 1990;31(12):14031406. doi:10.1136/gut.31.12.1403

62. Soeters PB, van Leeuwen PA. [Ammonia and glutamine metabolism of the intestine. The effect of lactulose and neomycin]. Infusionsther Klin Ernahr. 1986;13(4):186-190.

63. Weber FL Jr, Banwell JG, Fresard KM, Cummings JH. Nitrogen in fecal bacterial, fiber, and soluble fractions of patients with cirrhosis: effects of lactulose and lactulose plus neomycin. J Lab Clin Med. 1987;110(3):259-263.

64. Kang DJ, Kakiyama G, Betrapally NS, et al. Rifaximin exerts beneficial effects independent of its ability to alter microbiota composition. Clin Transl Gastroenterol. 2016;7(8):e187. doi:10.1038/ ctg. 2016.44

65. Hawkins RA, Jessy J, Mans AM, Chedid A, DeJoseph MR. Neomycin reduces the intestinal production of ammonia from glutamine. Adv Exp Med Biol. 1994;368::125-134. doi:10.1007/978-14615-1989-8 13

66. Pirotte J, Guffens JM, Devos J. Comparative study of basal arterial ammonemia and of orally-induced hyperammonemia in chronic portal systemic encephalopathy, treated with neomycin, lactulose, and an association of neomycin and lactulose. Digestion. 1974;10(6):435444. doi:10.1159/000197556 
67. Nicolao F, Efrati C, Masini A, Merli M, Attili AF, Riggio O. Role of determination of partial pressure of ammonia in cirrhotic patients with and without hepatic encephalopathy. $J$ Hepatol. 2003;38(4):441-446. doi:10.1016/s0168-8278(02)00436-1

68. Ong JP, Aggarwal A, Krieger D, et al. Correlation between ammonia levels and the severity of hepatic encephalopathy. Am J Med. 2003;114(3):188-193. doi:10.1016/s0002-9343(02)01477-8

69. Snady H, Feinman L. Prediction of variceal hemorrhage: a prospective study. Am J Gastroenterol. 1988;83(5):519-525.
70. Elgouhari HM, O'Shea R. What is the utility of measuring the serum ammonia level in patients with altered mental status? Cleve Clin J Med. 2009;76(4):252-254. doi:10.3949/ccjm.76a.08072

71. Ge PS, Runyon BA. Serum ammonia level for the evaluation of hepatic encephalopathy. JAMA. 2014;312(6):643-644. doi:10.1001/ jama.2014.2398

\section{Publish your work in this journal}

The International Journal of General Medicine is an international, peer-reviewed open-access journal that focuses on general and internal medicine, pathogenesis, epidemiology, diagnosis, monitoring and treatment protocols. The journal is characterized by the rapid reporting of reviews, original research and clinical studies across all disease areas. The manuscript management system is completely online and includes a very quick and fair peer-review system, which is all easy to use. Visit http://www.dovepress.com/ testimonials.php to read real quotes from published authors.

Submit your manuscript here: https://www.dovepress.com/international-journal-of-general-medicine-journal 